\title{
Factors associated with oral health-related quality of life of institutionalized elders
}

\section{Luiz Fabrício Santos de OLIVEIRA(a) iD $^{(a)}$}

Rayssa Lucena WANDERLEY(a) iD Elza Cristina Farias de ARAÚJO(a)

Mariana Marinho Davino de MEDEIROS(b) iD $^{(b)}$

Olívia Maria Costa de FIGUEREDO(b) iD

Mayara Abreu PINHEIRO(b) iD

Renata Cunha Matheus RODRIGUES GARCIA ${ }^{(b)}$ iD

Yuri Wanderley CAVALCANTI(a)

(a) Universidade Federal da Paraíba - UFPB, Graduate Program in Dentistry, Clinical and Social Dentistry Department. Federal University of Paraiba. João Pessoa, PB, Brazil.

(b) Universidade Estadual de Campinas Unicamp, Piracicaba School of Dentistry, Prosthodontics and Periodontology Department, Piraciaba, SP, Brazil.

Declaration of Interests: The authors certify that they have no commercial or associative interest that represents a conflict of interest in connection with the manuscript.

Corresponding Author:

Yuri Wanderley Cavalcanti

E-mail: yuri@ccs.ufpb.br

https://doi.org/10.1590/1807-3107bor-2021.vol35.0015

Submitted: February 12, 2020

Accepted for publication: July 27, 2020

Last revision: September 14, 2020
Abstract: This study aimed to evaluate the correlation between two Oral Health-Related Quality of Life (OHRQoL) questionnaires (the Oral Health Impact Profile (OHIP-14) and the Geriatric Oral Health Assessment Index (GOHAI)) and to investigate the factors associated with the OHRQoL of institutionalized elderly individuals. A cross-sectional multicenter study was performed with 344 institutionalized elderly individuals residing in two Brazilian cities. Six trained researchers interviewed the elderly individuals. Sociodemographic data were collected from medical records. Dental caries experience and the use of and need for dentures were recorded through oral examination performed by two trained examiners. A Likert scale (1-5 points) was used to assess general health and self-perceived oral health. The number of chewing cycles needed to chew a portion of peanuts was used to assess the swallowing threshold. The OHIP-14 and GOHAI were used to evaluate OHRQoL, and statistically significant correlations were assessed using Spearman's correlation test $(p<0.05)$. Poisson regression $(p<0.05)$ was used to investigate the association of OHRQoL with independent variables. Scores on the OHIP-14 (7.57 \pm 8.63) and GOHAI (32.46 \pm 3.85$)$ were strongly and inversely correlated $\left(r^{2}=-0.671, p<0.001\right)$, although these measures were associated with different factors. A higher OHIP14 total score (worse OHRQoL) was associated with female gender, a greater number of healthy teeth, worse self-perceived general health and oral health, and a lower swallowing threshold $(\mathrm{p}<0.05)$. A higher GOHAI total score (better OHRQoL) was associated with a greater number of filled teeth, better self-perceived oral health and a greater swallowing threshold $(p<0.05)$. In conclusion, worse OHRQoL among institutionalized elderly individuals is associated with worse self-perceived oral health and a greater swallowing threshold.

Keywords: Quality of Life; Oral Health; Geriatrics; Nursing Homes.

\section{Introduction}

Brazil is undergoing a demographic transition characterized by a significant increase in the elderly population, following the global trend. ${ }^{1}$ This change in the Brazilian population age profile leads to elderly individuals moving from their community to long-term care institutions 
for elderly individuals, resulting in an increase in the institutionalization rate of elderly individuals. ${ }^{2}$ Although some long-term institutions for elderly individuals are private, most long-term institutions in Brazil are nonprofit and nongovernmental organizations that welcome elderly individuals with limitations to perform daily living activities. ${ }^{3}$

In contrast to the increase in institutionalization rates, few public policies are related to institutionalized elderly individuals. ${ }^{4}$ In addition, few caregivers are trained to perform oral care for dependent institutionalized elderly individuals. ${ }^{4,5}$ Nevertheless, these factors can impair the oral health of such a population. ${ }^{5}$ In this context, poorer oral health conditions have been reported in elderly individuals residing in long-term care institutions. ${ }^{6,7}$ When compared to community dwelling elderly individuals, institutionalized elderly individuals presented a higher number of decayed and missed teeth, in addition to a higher frequency of periodontal disease. ${ }^{6,7}$

Therefore, oral disorders among institutionalized elderly individuals may influence their oral healthrelated quality of life (OHRQoL). ${ }^{6}$ A recent systematic review showed that institutionalized elderly individuals present worse health-related quality of life than community dwelling elderly individuals, although the findings regarding OHRQoL were not conclusive. ${ }^{8}$ OHRQoL refers to the influence of oral disorders on an individual's physical, functional, psychological and social well-being., $90,11,12$ Therefore, the concept of oral health goes beyond maintaining healthy teeth and is necessary to guarantee the elderly individuals' OHRQoL..$^{12,13}$

Some questionnaires, such as the Oral Health Impact Profile (OHIP) and the Geriatric Oral Health Assessment Index (GOHAI), have been used to evaluate elderly individuals' OHRQoL. ${ }^{10,12}$ In addition, previous investigations seek to identify the factors associated with the elderly individuals' OHRQoL under different circumstances. ${ }^{14,15,16,17}$ However, few multicenter studies have investigated the factors associated with the OHRQoL of institutionalized elderly individuals using different instruments. Therefore, this study aimed to a) evaluate the correlation between the OHIP-14 and the GOHAI to assess institutionalized elderly individuals' OHRQoL and b) investigate the factors associated with the impairment of institutionalized elderly individuals' OHRQoL from a multicenter perspective.

\section{Methodology}

\section{Ethical aspects}

Institutional Research Ethics Committees approved the present study under protocol numbers 66122917.6.1001.5188 and 66122917.6.3001.5418, in agreement with the Helsinki Declaration of 1964 and its posterior alterations. All the participants agreed and signed a consent form.

\section{Study design, setting and participants}

This cross-sectional study included 141 elderly residents of 7 long-term care institutions located in the city of João Pessoa (PB) and 203 elderly residents of 10 long-term care institutions in the city of Piracicaba (SP). The sample size $(\mathrm{n}=344)$ was considered appropriate for the study, considering that the minimum number of elderly individuals required for the investigation would be 303 . Sample size calculation considered a universe 848 institutionalized elderly individuals, a $50 \%$ response rate, a 95\% confidence interval, a design effect of 1.5 , and a statistical power of $80 \%$.

The inclusion criteria were institutionalized elderly individuals aged 60 years or over and residing in a long-term care institution in João Pessoa or Piracicaba. Any communication, neurological and/or cognitive impairment was set as exclusion criteria. The presence of neurological and/or cognitive disorders was determined using the Mini Mental State Examination (MMSE). ${ }^{18,19}$ This questionnaire assessed orientation; memory; attention; the ability to name, follow verbal and written commands; and the ability to write a sentence and copy a drawing, resulting in a final score (0-30 points). Elderly individuals with an MMSE final score lower than 13 points were excluded from the study. ${ }^{20}$

\section{Data collection, instruments and study variables}

Sociodemographic characteristics such as gender, age and institutionalization time were collected from the records of elderly individuals' institutions. The elderly individuals' oral health condition was assessed according to the dental caries experience and use 
of and need for dentures. Oral examinations were conducted under natural light by two independent examiners, who used appropriate personal protective equipment. Oral clinical exams were performed using a World Health Organization (WHO) probe and a clinical mirror (GOLGRAN Ind Com Instr Odontológicos, São Caetano do Sul, Brazil). The examiners were calibrated to assess the dental caries experience and trained to evaluate the use of and need for dentures. Considering that the examiners are from different cities, a joint calibration was organized and performed. In addition, the calibration was divided into two stages: theoretical and clinical. The criteria for dental caries diagnosis were established during theoretical training, and 20 noninstitutionalized elderly individuals were evaluated during the clinical stage. At the end of the calibration process, the intraexaminer and interexaminer Kappa values obtained were 0.93 and 0.84 , respectively.

The dental caries experience was evaluated according to the WHO criteria by using the decayed, missing and filled teeth index (DMFT). ${ }^{21}$ The use of dentures was classified as positive when the elder was using the denture at the time of the oral examination. Individuals without teeth and without dentures, or those who needed to have their dentures replaced, were positive for the evaluation of denture need. The elderly individuals' self-perception regarding their general health and their oral health were measured using a Likert scale (1-5 points), where one point indicated worse self-perception and five points represented better self-perception.

The swallowing threshold was assessed using a portion of roasted peanuts $(3.7 \mathrm{~g})$. Volunteers were asked to chew the portion of peanuts until they fell they were ready to swallow. Two trained researchers conducted this test and counted the number of chewing cycles performed by the volunteers until the swallowing moment. ${ }^{22,23}$ Before testing, the elderly individuals were asked whether they had an allergy to and the ability to chew peanuts. The allergic volunteers did not have the swallowing threshold assessed and were considered missing data. Elderly individuals without teeth and without dentures were considered unable to chew and had the swallowing threshold recorded as zero chewing cycles.
The OHIP-14 (the short form of the OHIP) ${ }^{10,24}$ and the GOHAI ${ }^{11,12}$ were used to assess OHRQoL. The OHIP-14 is a 14-item questionnaire in which the respondents reports how often (never, hardly ever, occasionally, fairly often or very often) his/her oral health impacts the OHRQoL regarding the following domains: functional limitation, physical pain, psychological discomfort, physical disability, psychological disability, social disability and handicap. ${ }^{10,24}$ The GOHAI is a 12-item questionnaire in which the respondent reports how often (always, sometimes or never) his/her oral health influences OHRQoL regarding physical function, psychological aspects, and pain and discomfort. ${ }^{11,12}$ The OHIP-14 and the GOHAI generate a total score that can range from zero to 56 points and from 12 to 36 points, respectively. For the OHIP-14, a higher total score means worse OHRQoL, while a higher score on the GOHAI means better OHRQoL.

\section{Data analysis}

Data were analyzed using IBM Statistical Package for the Social Sciences software (IBM SPSS, v. 20, Chicago, USA). The dependent variables of the study were the total score of the OHIP-14 and the GOHAI. Initially, data were analyzed descriptively to obtain the median and interquartile range. Spearman's correlation test was used to assess the correlation between the total scores of the OHIP-14 and the GOHAI. Independent $t$ tests were used to compare the OHRQoL results between the two cities of the study. Poisson multiple regression models were used to investigate the variables associated with the total scores of the OHIP-14 and the GOHAI. The independent variables used to construct the multivariate model were gender; age; institutionalization time; use of and need for upper/lower dentures; number of healthy, decayed, missing and filled teeth; and self-perceived general and oral health. The variables that had a p-value $>0.20$ were removed for adjustment purposes. The variables that had a $p$-value $<0.05$ in the adjusted model were considered statistically significant. Prevalence Ratio values (PRs) and confidence intervals (95\% CIs) were obtained for unadjusted and adjusted models. The regression coefficient B was used to estimate the effect of each independent variable on the dependent variable $(\mathrm{p}<0.05)$. 
- Factors associated with oral health-related quality of life of institutionalized elders

\section{Results}

The participants in the study were mostly female $(n=206,59.9 \%)$, with an average age of 77.73 years (Tables 1 and 2). The use of upper dentures was observed in $57.6 \%$ of participants, while the use of lower dentures was observed in $34.1 \%$. The frequency of participants who needed upper and lower dentures was $88.2 \%$ and $89.7 \%$, respectively (Table 1 ). The median time of institutionalization was 33 months. Dental caries experience was characterized by a high number of missing teeth and a low number of healthy teeth. The elderly individuals' self-perceived general health and oral health was high (median $=4$ ). The median OHRQoL measured by the OHIP-14 was considered low, and the OHRQoL measured by the GOHAI was considered high (Table 2).

A strong inverse correlation $\left(\mathrm{p}<0.001, \mathrm{r}^{2}=-0.671\right)$ was observed between the total scores on the OHIP-14 and scores on the GOHAI. Thus, a higher total score on the OHIP-14 (worse OHRQoL) was correlated with a lower final score on the GOHAI (worse OHRQoL), highlighting that the results of these instruments were compatible. Elderly individuals residing in long-term care institutions on João Pessoa (mean $=7, \mathrm{SD}=9$ ) and Piracicaba (mean $=8, \mathrm{SD}=9$ ) presented similar OHIP-14 scores $(\mathrm{t}=-0.743, \mathrm{df}=342, \mathrm{p}>0.05)$. However, the elderly individuals residing in long-term care institutions in João Pessoa (mean $=34, \mathrm{SD}=3$ ) presented better GOHAI scores than the institutionalized elderly
Table 1. Distribution of the participants of the study regarding gender and the use of and need for removable dentures.

\begin{tabular}{lcc} 
Variable & $\mathrm{n}$ & $\%$ \\
\hline Gender & 138 & 40.1 \\
Male & 206 & 59.9 \\
$\quad$ Female & & \\
Use of upper dentures & 196 & 57.6 \\
$\quad$ Yes & 144 & 42.4 \\
No & & \\
Need for upper dentures & 300 & 88.2 \\
Yes & 40 & 11.8 \\
No & & \\
Use of lower dentures & 116 & 34.1 \\
Yes & 224 & 65.9 \\
No & & \\
Need for lower dentures & 305 & 89.7 \\
Yes & 35 & 10.3 \\
No &
\end{tabular}

individuals in Piracicaba city (mean $=31, \mathrm{SD}=4$; $\mathrm{t}=6.725, \mathrm{df}=332.965, \mathrm{p}<0.001$ ).

The adjusted Poisson multivariate regression model revealed that a greater impact on OHRQoL (higher OHIP-14 total score) was associated with female sex, a greater number of healthy teeth, a lower swallowing threshold, lower self-perceived general health and lower self-perceived oral health ( $p<0.05$ - Table 3). Better self-perceived OHRQoL (greater GOHAI total score) was associated with a greater number of filled teeth, a greater swallowing threshold and better self-perceived oral health $(\mathrm{p}<0.05$ - Table 4$)$.

Table 2. Descriptive of the quantitative variables included in the study.

\begin{tabular}{|c|c|c|c|c|}
\hline Variable & Mean & Standard deviation & Median & Quartile 25-75 \\
\hline Age (years) & 77.73 & 9.10 & 77.00 & $71.00-84.50$ \\
\hline Time of institutionalization (months) & 55.64 & 63.43 & 33.00 & $14.00-80.00$ \\
\hline Number of healthy teeth & 2.65 & 4.64 & 0.00 & $0.00-4.00$ \\
\hline Number of decayed teeth & 1.46 & 2.96 & 0.00 & $0.00-2.00$ \\
\hline Number of missing teeth & 26.37 & 7.89 & 32.00 & $23.00-32.00$ \\
\hline Number of filled teeth & 1.32 & 3.12 & 0.00 & $0.00-1.00$ \\
\hline Self-perceived overall health (scale: 1 to 5 ) & 3.95 & 1.12 & 4.00 & $3.00-5.00$ \\
\hline Self-perceived oral health (scale: 1 to 5 ) & 3.81 & 1.32 & 4.00 & $3.00-5.00$ \\
\hline Swallowing threshold & 38.80 & 54.16 & 0.00 & $0.00-68.50$ \\
\hline OHIP-14 total score & 7.58 & 8.65 & 5.00 & $0.00-11.00$ \\
\hline GOHAl total score & 32.44 & 3.86 & 34.00 & $31.00-35.00$ \\
\hline
\end{tabular}


Table 3. Unadjusted and adjusted models of Poisson multivariate regression to investigate the factors associated with OHRQoL (measured by OHIP-1 4 questionnaire) among institutionalized elderly individuals in the cities of João Pessoa and Piracicaba, Brazil (2019).

\begin{tabular}{|c|c|c|c|c|c|c|c|c|c|c|}
\hline \multirow{3}{*}{ Variable } & \multicolumn{5}{|c|}{ Unadjusted model (all variables) } & \multicolumn{5}{|c|}{ Adjusted model (variables with $p<0.20$ ) } \\
\hline & \multirow{2}{*}{ B } & \multirow{2}{*}{$\mathrm{p}$-value } & \multirow{2}{*}{ PR } & \multicolumn{2}{|c|}{$95 \% \mathrm{Cl}$} & \multirow{2}{*}{ B } & \multirow{2}{*}{$p$-value } & \multirow{2}{*}{ PR } & \multicolumn{2}{|c|}{$95 \% \mathrm{Cl}$} \\
\hline & & & & Lower & Upper & & & & Lower & Upper \\
\hline Intercept & 0.131 & 0.976 & 1.140 & 0.000 & 5.670 .071 & 2.618 & $<0.001$ & 13.703 & 3.339 & 56.230 \\
\hline \multicolumn{11}{|l|}{ Gender } \\
\hline Male & -0.273 & 0.036 & 0.761 & 0.590 & 0.982 & -0.257 & 0.038 & 0.773 & 0.606 & 0.986 \\
\hline Female & Ref. & & Ref. & & & Ref. & & Ref. & & \\
\hline \multicolumn{11}{|l|}{ Use of upper dentures } \\
\hline Yes & 0.019 & 0.898 & 1.019 & 0.760 & 1.367 & & & & & \\
\hline No & Ref. & & Ref. & & & & & & & \\
\hline \multicolumn{11}{|l|}{ Need for upper dentures } \\
\hline Yes & 0.384 & 0.159 & 1.468 & 0.861 & 2.505 & & & & & \\
\hline No & Ref. & & Ref. & & & & & & & \\
\hline \multicolumn{11}{|l|}{ Use of lower dentures } \\
\hline Yes & -0.047 & 0.787 & 0.954 & 0.681 & 1.338 & & & & & \\
\hline No & Ref. & & Ref. & & & & & & & \\
\hline \multicolumn{11}{|l|}{ Need for lower dentures } \\
\hline Yes & -0.549 & 0.042 & 0.577 & 0.340 & 0.979 & & & & & \\
\hline No & Ref. & & Ref. & & & & & & & \\
\hline Age & -0.009 & 0.248 & 0.991 & 0.977 & 1.006 & & & & & \\
\hline Time of institutionalization & -0.001 & 0.457 & 0.999 & 0.998 & 1.001 & & & & & \\
\hline Number of healthy teeth & 0.172 & 0.203 & 1.187 & 0.911 & 1.547 & 0.062 & 0.023 & 1.064 & 1.008 & 1.124 \\
\hline Number of decayed teeth & 0.111 & 0.415 & 1.118 & 0.856 & 1.460 & & & & & \\
\hline Number of missing teeth & 0.136 & 0.306 & 1.145 & 0.883 & 1.485 & 0.029 & 0.193 & 1.029 & 0.986 & 1.075 \\
\hline Number of filled teeth & 0.061 & 0.661 & 1.062 & 0.810 & 1.393 & & & & & \\
\hline Self-perceived overall health & -0.195 & 0.000 & 0.822 & 0.750 & 0.902 & -0.155 & 0.001 & 0.856 & 0.781 & 0.939 \\
\hline Self-perceived oral health & -0.185 & 0.000 & 0.831 & 0.771 & 0.896 & -0.205 & $<0.001$ & 0.815 & 0.758 & 0.876 \\
\hline Swallowing threshold & -0.002 & 0.073 & 0.998 & 0.995 & 1.000 & -0.003 & 0.014 & 0.997 & 0.994 & 0.999 \\
\hline
\end{tabular}

B: regression coefficient; PR: prevalence ratio; $95 \% \mathrm{Cl}$ : 95\% confidence interval; Ref.: reference category used in the regression.

\section{Discussion}

The results of the present study demonstrate that better OHRQoL of institutionalized elderly individuals was associated with clinical parameters and self-perceived oral health. This is the first study to use both the OHIP-14 and the GOHAI to evaluate OHRQoL in Brazilian institutionalized elderly individuals. Previous studies reported a strong correlation between the final scores of the OHRQoL questionnaires but examined different age groups and populations. ${ }^{25,26}$ The statistically significant inverse correlation observed between OHIP-14 and GOHAI scores may suggest collinearity between these instruments. However, despite the strong inverse correlation $(\mathrm{p}<0.001, \mathrm{r} 2=-0.671)$, different OHRQoL-related factors were associated with the OHIP-14 and the GOHAI.

The use of more than one instrument for assessing OHRQoL is important because OHRQoL is a complex entity that requires the evaluation of many composing factors. Under this perspective, the $\mathrm{OHIP}-14$ questionnaire assesses the impact of oral health conditions on QoL, while the GOHAI questionnaire analyzes the influence of elderly individuals' self-perceived oral health on OHRQoL. Therefore, these instruments are complementary and need to be used alongside to offer a better comprehension of the OHRQoL.

The results of this study present an overview of the institutionalized elderly individuals' OHRQoL 
Table 4. Unadjusted and adjusted models of Poisson multivariate regression to investigate the factors associated with $O H R Q$ (measured by the GOHAl questionnaire) among institutionalized elderly individuals in the cities of João Pessoa and Piracicaba, Brazil (2019).

\begin{tabular}{|c|c|c|c|c|c|c|c|c|c|c|}
\hline \multirow{3}{*}{ Variable } & \multicolumn{5}{|c|}{ Not adjusted model (all variables) } & \multicolumn{5}{|c|}{ Adjusted model (variables with $p<0.20$ ) } \\
\hline & \multirow{2}{*}{ B } & \multirow{2}{*}{$\mathrm{p}$-value } & \multirow{2}{*}{ PR } & \multicolumn{2}{|c|}{$95 \% \mathrm{Cl}$} & \multirow{2}{*}{ B } & \multirow{2}{*}{$p$-value } & \multirow{2}{*}{ PR } & \multicolumn{2}{|c|}{$95 \% \mathrm{Cl}$} \\
\hline & & & & Lower & Upper & & & & Lower & Upper \\
\hline Intercept & & $<0.001$ & 26.095 & 18.662 & 36.489 & 3.239 & $<0.001$ & 25.500 & 22.266 & 29.204 \\
\hline \multicolumn{11}{|l|}{ Gender } \\
\hline Male & & 0.535 & 0.991 & 0.964 & 1.019 & & & & & \\
\hline Female & & & Ref. & & & & & & & \\
\hline \multicolumn{11}{|l|}{ Use of upper dentures } \\
\hline Yes & & 0.855 & 0.997 & 0.965 & 1.030 & & & & & \\
\hline No & & & Ref. & & & & & & & \\
\hline \multicolumn{11}{|l|}{ Need for upper dentures } \\
\hline Yes & & 0.003 & 0.945 & 0.910 & 0.981 & -0.027 & 0.105 & 0.974 & 0.943 & 1.006 \\
\hline No & & & Ref. & & & Ref. & & Ref. & & \\
\hline \multicolumn{11}{|l|}{ Use of lower dentures } \\
\hline Yes & & 0.307 & 0.983 & 0.950 & 1.016 & & & & & \\
\hline No & & & Ref. & & & & & & & \\
\hline \multicolumn{11}{|l|}{ Need for lower dentures } \\
\hline Yes & & 0.228 & 1.026 & 0.984 & 1.069 & & & & & \\
\hline No & & & Ref. & & & & & & & \\
\hline Age & 0.001 & 0.275 & 1.001 & 0.999 & 1.002 & 0.001 & 0.110 & 1.001 & 1.000 & 1.003 \\
\hline Time of institutionalization & 0.000 & 0.235 & 1.000 & 1.000 & 1.000 & & & & & \\
\hline Number of healthy teeth & -0.003 & 0.580 & 0.997 & 0.986 & 1.008 & -0.003 & 0.064 & 0.997 & 0.993 & 1.000 \\
\hline Number of decayed teeth & 0.004 & 0.483 & 1.004 & 0.993 & 1.014 & 0.004 & 0.054 & 1.004 & 1.000 & 1.007 \\
\hline Number of missing teeth & 0.000 & 0.968 & 1.000 & 0.991 & 1.010 & & & & & \\
\hline Number of filled teeth & 0.007 & 0.198 & 1.007 & 0.997 & 1.017 & 0.005 & 0.021 & 1.005 & 1.001 & 1.010 \\
\hline Self-perceived overall health & 0.011 & 0.095 & 1.011 & 0.998 & 1.025 & 0.011 & 0.087 & 1.011 & 0.998 & 1.024 \\
\hline Self-perceived oral health & 0.030 & 0.000 & 1.031 & 1.020 & 1.042 & 0.031 & $<0.001$ & 1.031 & 1.020 & 1.042 \\
\hline Swallowing threshold & 0.000 & 0.007 & 1.000 & 1.000 & 1.000 & 0.000 & 0.014 & 1.000 & 1.000 & 1.000 \\
\hline
\end{tabular}

B: regression coefficient; PR: prevalence ratio; $95 \% \mathrm{Cl}$ : 95\% confidence interval; Ref.: reference category used in the regression.

from a Brazilian northeastern capital and from an important city of São Paulo Countryside. The regional and socioeconomic differences between those two cities allow a broader and more diverse analysis of institutionalized elderly individuals from Brazil. Therefore, the results from this study present a greater representativeness of the Brazilian elderly institutionalized population.

Elderly individuals residing in long-term care institutions in João Pessoa presented a better OHRQoL than those living in institutions in Piracicaba, according to scores on the GOHAI. The GOHAI evaluates selfperceived oral health and its influence on OHRQoL. Self-perceived oral health could be influenced by individuals' education level. ${ }^{12}$ Institutionalized elderly individuals in Piracicaba had more years of education than those living in João Pessoa (data not shown). Therefore, it could be hypothesized that due to the higher educational level, the institutionalized elderly individuals from Piracicaba were more aware of the presence of oral problems and thus more aware of their influence on physical, functional and psychological aspects.

The present study resembles the profile of Brazilian elderly individuals in the literature (female, above 75 years). ${ }^{1,2,27}$ This prevalence may be explained by the fact that women face greater life expectancy and may become widowed earlier and do not have children, increasing the institutionalization risk. ${ }^{28}$ We must acknowledge that the institutionalized 
elderly individuals' profile is of individuals in a situation of social exclusion and absence of family support. ${ }^{29}$ Therefore, the predominance of women in the study sample reinforces the social profile of the institutionalized elderly individuals. Lower OHRQoL observed in females may be related to a greater worry with their own health status in comparison to men, suggesting a greater perceived health problems. ${ }^{30}$

Similar to observations in the present study, previous surveys observed that Brazilian institutionalized elderly individuals present poorer oral health, characterized by a high prevalence of tooth loss and denture need. ${ }^{28,31}$ It is important to point out that the oral health of the institutionalized population is the result of unequal public oral health assistance, limited access to oral care and unequal prevalence distribution of oral health problems throughout the years. ${ }^{13,28,29}$

Although the prevalence of tooth loss is high and the use of dentures is low, most of the elderly individuals positively evaluated their oral health conditions through the numeric scale, becoming a paradox when comparing their oral health status with their self-perception. It is important to emphasize that self-perception takes into consideration the social determinants of the individuals, as well as the concepts about health that were built by these elderly individuals throughout the years. ${ }^{25,26,32}$ Although they exhibit poor oral health, the elderly present other health concerns that end up taking a priority in their self-perception and influence on OHRQoL. Despite presenting poor oral health status and the presence of pain, elderly individuals positively evaluate their oral health, accepting these conditions as typical for advanced age, disconnecting the concept of aging from the OHRQoL. ${ }^{33}$

Another intriguing discovery is the greater impact on oral health associated with the presence of healthy teeth. This aspect may be related to the presence of pain, periodontal disease and other health disorders related to remaining teeth. ${ }^{29}$ Previous studies show that elderly individuals tend to associate OHRQoL with the absence of pain symptoms, suppressing the damage caused by the absence of teeth. ${ }^{34}$ Furthermore, the low relevance of oral health and the preservation of remaining teeth are highlighted, since oral problems are considered secondary in comparison to other health issues. ${ }^{28,34}$

The absence of teeth is not associated with an impact on the nutritional status of institutionalized elderly individuals. ${ }^{35}$ In addition, differences in the OHRQoL of institutionalized elderly individuals were not observed according to the number of remaining teeth. ${ }^{35}$ Divergent results have been verified in noninstitutionalized elderly individuals, in which the impact of tooth loss on nutritional status and $\mathrm{OHRQOL}$ has been found. ${ }^{36}$ These findings strengthen that oral health has a secondary role in the OHRQoL of institutionalized elderly individuals. Nonetheless, the results of this study indicate that some clinical parameters can influence OHRQoL. Therefore, reducing the impact of these oral problems disorders is necessary.

As an example, it was observed that the presence of filled teeth and greater swallowing threshold was associated with a better OHRQoL. For that matter, strategies for reducing or eliminating the need for dental treatment, as well as improving the chewing capacity of the institutionalized elderly individuals, tend to contribute to a better OHRQoL of these elderly individuals. ${ }^{17}$ Nevertheless, none of the institutions visited during the study included dentists in the staff responsible for the elderly individuals' oral care. This reinforces the secondary importance given to oral health, which is often seen as an entity separated from overall health.

The present study presented some limitations. The cross-sectional design does not allow the estimation of precise cause-effect associations. In addition, the absence of accurate sociodemographic variables hinders the diagnosis of the institutionalized elderly individuals' reality in Brazil. Memory bias may also interfere with the results of OHRQoL. This is of relevance for institutionalized elderly individuals, who are frequently untied from social, spatial and temporal reality.

One of the strengths of the study is the heterogeneous sample, which included individuals from two different regions of Brazil and displayed distinct sociodemographic and economic environments. Therefore, this is not a local investigation but instead provides more solid evidence of the factors associated 
with the OHRQoL of institutionalized elderly individuals in Brazil. Longitudinal studies must be performed to evaluate the latency of the associated factors and the fluctuation of the OHRQoL over time, in addition to studies of qualitative approaches that may enrich the diagnosis of the factors associated with a better quality of life.

\section{Conclusion}

Scores on the OHIP-14 and the GOHAI were correlated, and both questionnaires were used to assess
OHRQoL. A worse OHRQoL was associated with worse self-perceived oral health and a greater swallowing threshold. These factors must be considered to offer better life conditions and dignity for this population.

\section{Acknowledgments}

We thank all long-term care institutions for giving us authorization for data collection. The authors thank CAPES (Coordenação de Aperfeiçoamento de Pessoal de Nivel Superior - Finance code 001) for graduate program support. The authors also thankFAPESP(Proccess number 18/06185-6) for MSc scholarship granted to MMDM.

\section{References}

1. Dalazen CE, Bomfim RA, De-Carli AD. [Factors behind self-perceived need for dental treatment and prosthesis in Brazilian elderly people]. Cien Saude Colet. 2018 Mar;23(3):945-52. Portuguese. https://doi.org/10.1590/1413-81232018233.09682016

2. Melo LA, Sousa MM, Medeiros AK, Carreiro AD, Lima KC. Factors associated with negative self-perception of oral health among institutionalized elderly. Cien Saude Colet. 2016 Nov;21(11):3339-46. https://doi.org/10.1590/1413-812320152111.08802015

3. Petersen PE, Yamamoto T. Improving the oral health of older people: the approach of the WHO Global Oral Health Programme. Community Dent Oral Epidemiol. 2005 Apr;33(2):81-92. https://doi.org/10.1111/j.1600-0528.2004.00219.x

4. Pessoa DM, Pérez G. Mari-Dell'Olmo M, Cornejo-Ovalle M, Borrell C, Piuzevam G, Lima KC. Comparative study of the oral health profile of institutionalized elderly persons in Brazil and Barcelona, Spain. Rev Bras Geriatr Gerontol. 2016;19(5):723-32. https://doi.org/10.1590/1809-98232016019.160013

5. Eustaquio-Raga MV, Montiel-Company JM, Almerich-Silla JM. Factors associated with edentulousness in an elderly population in Valencia (Spain). Gac Sanit. 2013 Mar-Apr;27(2):123-7. https://doi.org/10.1016/i.gaceta.2012.02.009

6. Niesten D, Witter D, Bronkhorst E, Creugers N. Oral health-related quality of life and associated factors in a care-dependent and a care-independent older population. J Dent. 2016 Dec;55:33-9. https://doi.org/10.1016/i.jdent.2016.09.007

7. Farias IP, Sousa SA, Almeida LF, Santiago BM, Pereira AC, Cavalcanti YW. Does non-institutionalized elders have a better oral health status compared to institutionalized ones? A systematic review and meta-analysis. Cien Saude Colet. 2020 Jun;25(6):2177-92. https://doi.org/10.1590/1413-81232020256.18252018

8. Medeiros MM, Carletti TM, Magno MB, Maia LC, Cavalcanti YW, Rodrigues-Garcia RC. Does the institutionalization influence elderly's quality of life? A systematic review and meta-analysis. BMC Geriatr. 2020 Feb;20(1):44. https://doi.org/10.1186/s12877-020-1452-0

9. Slade GD. Derivation and validation of a short-form oral health impact profile. Community Dent Oral Epidemiol. 1997 Aug;25(4):284-90. https://doi.org/10.1111/j.1600-0528.1997.tb00941.x

10. Oliveira BH, Nadanovsky P. Psychometric properties of the Brazilian version of the Oral Health Impact Profile-short form. Community Dent Oral Epidemiol. 2005 Aug;33(4):307-14. https://doi.org/10.1111/j.1600-0528.2005.00225.x

11. Atchison KA, Dolan TA. Development of the Geriatric Oral Health Assessment Index. J Dent Educ. 1990 Nov; 54(11):680-7. https://doi.org/10.1002/i.0022-0337.1990.54.11.tb02481.x PMID:2229624

12. Silva SR, Castellanos Fernandes RA. [Self-perception of oral health status by the elderly]. Rev Saude Publica. 2001 Aug;35(4):349-55. Portuguese. https://doi.org/10.1590/S0034-89102001000400003

13. Corrêa HW, Bitencourt FV, Nogueira AV, Toassi RF. Saúde bucal em usuários da atenção primária: análise qualitativa da autopercepção relacionada ao uso e necessidade de prótese dentária. Physis. 2016;26(2):503-24. https://doi.org/10.1590/S0103-73312016000200009

14. Kahar P, Chapman C, Gupta J. Assessment of the Effect of Oral Health on Quality of Life and Oral-Health Indicators among ESRD Patients in Southwest Florida: A Pilot Study. Int J Dent. 2019 Sep;2019:1608329. https://doi.org/10.1155/2019/1608329

15. Lantto A, Lundqvist R, Wårdh I. Quality of life related to tooth loss and prosthetic replacements among persons with dependency and functional limitations. Acta Odontol Scand. 2020 Apr;78(3):173-180. https://doi.org/10.1080/00016357.2019.1668054 
16. Adamo D, Pecoraro G, Fortuna G, Amato M, Marenzi G, Aria M, et al. Assessment of oral health-related quality of life, measured by OHIP-14 and GOHAl, and psychological profiling in burning mouth syndrome: a case-control clinical study. J Oral Rehabil. 2020 Jan;47(1):42-52. https://doi.org/10.1111/joor.12864

17. Pattussi MP, Peres KG, Boing AF, Peres MA, Costa JS. Self-rated oral health and associated factors in Brazilian elders. Community Dent Oral Epidemiol. 2010 Aug;38(4):348-59. https://doi.org/10.1111/j.1600-0528.2010.00542.x

18. Folstein MF, Folstein SE, McHugh PR. "Mini-mental state": a practical method for grading the cognitive state of patients for the clinician. J Psychiatr Res. 1975 Nov;12(3):189-98. https://doi.org/10.1016/0022-3956(75)90026-6

19. de Melo DM, Barbosa AJ. [Use of the Mini-Mental State Examination in research on the elderly in Brazil: a systematic review]. Cien Saude Colet. 2015 Dec;20(12):3865-76. Portuguese. https://doi.org/10.1590/1413-812320152012.06032015

20. Bertolucci PH, Brucki SM, Campacci SR, Juliano Y. [The Mini-Mental State Examination in a general population: impact of educational status]. Arq Neuropsiquiatr. 1994 Mar;52(1):1-7. Portuguese. https://doi.org/10.1590/S0004-282X1994000100001

21. World Health Organization - WHO. Oral health surveys: Basic methods. 5th ed. Geneva: WHO; 2013.

22. Campos CH, Gonçalves TM, Rodrigues Garcia RC. Implant retainers for free-end removable partial dentures affect mastication and nutrient intake. Clin Oral Implants Res. 2014 Aug;25(8):957-61. https://doi.org/10.1111/clr.12165

23. Engelen L, Fontijn-Tekamp A, Bilt A. The influence of product and oral characteristics on swallowing. Arch Oral Biol. 2005 Aug;50(8):739-46. https://doi.org/10.1016/j.archoralbio.2005.01.004

24. Souza EH, Barbosa MB, Oliveira PA, Espíndola J, Gonçalves KJ. [Impact of oral health in the daily life of institutionalized and non institutionalized elder in the city of Recife (PE, Brazil)]. Cien Saude Colet. 2010 Sep;15(6):2955-64. Portuguese. https://doi.org/10.1590/S1413-81232010000600034

25. Tristiu R, Vesa S, Dumitru RB, Arweiler NB, Cosgarea RM, Lascu L, et al. Association of oral-health related quality of life and general health assessment in patients with rheumatoid arthritis. Oral Health Prev Dent. 2018;16(3):271-80. https://doi.org/10.3290/i.ohpd.a39912

26. Azevedo MS, Correa MB, Azevedo JS, Demarco FF. Dental prosthesis use and/or need impacting the oral healthrelated quality of life in Brazilian adults and elders: results from a National Survey. J Dent. 2015 Dec;43(12):1436-41. https://doi.org/10.1016/i.jdent.2015.10.016

27. Pinheiro NC, Holanda VC, Melo LA, Medeiros AK, Lima KC. Inequality in the characteristics of the institutionalized elderly in the city of Natal, Brazil. Cien Saude Colet. 2016 Nov;21(11):3399-405. https://doi.org/10.1590/1413-812320152111.19472015

28. Piuvezam G, de Lima KC. Self-perceived oral health status in institutionalized elderly in Brazil. Arch Gerontol Geriatr. 2012 Jul-Aug;55(1):5-11. https://doi.org/10.1016/i.archger.2011.04.017

29. Piuvezam G, de Lima KC. Factors associated with missing teeth in the Brazilian elderly institutionalised population. Gerodontology. 2013 Jun;30(2):141-9. https://doi.org/10.1111/j.1741-2358.2012.00655.x

30. Martins AM, Jones KM, Souza JG, Pordeus IA. [Association between physical and psychosocial impacts of oral disorders and quality of life among the elderly]. Cien Saude Colet. 2014 Aug;19(8):3461-78. Portuguese. https://doi.org/10.1590/1413-81232014198.16202013

31. Petrovski M, Ivanovski K, Minovska A. DMFT index among institutionalized elderly. Balk J Dent Med. 2015;19(1):21-5. https://doi.org/10.1515/bjdm-2015-0029

32. Saliba TA, Ortega MM, Goya KK, Moimaz SA, Garbin CA. Influence of oral health on the quality of life of institutionalized and noninstitutionalized elderly people. Dent Res J (Isfahan). 2018 Jul-Aug;15(4):256-63.

33. Haikal DS, Paula AM, Martins AM, Moreira AN, Ferreira EF. [Self-perception of oral health and impact on quality of life among the elderly: a quantitative-qualitative approach]. Cien Saude Colet. 2011 Jul;16(7):3317-29. Portuguese. https://doi.org/10.1590/S1413-81232011000800031

34. Hassel AJ, Koke U, Schmitter M, Rammelsberg P. Factors associated with oral health-related quality of life in institutionalized elderly. Acta Odontol Scand. 2006 Feb;64(1):9-15. https://doi.org/10.1080/00016350500326211

35. Andrade FB, Caldas Junior AF, Kitoko PM. Relationship between oral health, nutrient intake and nutritional status in a sample of Brazilian elderly people. Gerodontology. 2009 Mar;26(1):40-5. https://doi.org/10.1111/j.1741-2358.2008.00220.x

36. Bomfim RA, Frias AC, Cascaes AM, Pereira AC. Functional dentition and associated factors in Brazilian elderly people: A multilevel generalised structural equation modelling approach. Gerodontology. 2018 Dec;35(4):350-8. https://doi.org/10.1111/ger.12355 